\title{
Managing hypercholesterolemia and preventing cardiovascular events in elderly and younger Chinese adults: focus on rosuvastatin
}

This article was published in the following Dove Press journal:

Clinical Interventions in Aging

6 December 2013

Number of times this article has been viewed

\section{Zhen Wang \\ Junbo $\mathrm{Ge}$}

Department of Cardiology, Zhongshan Hospital, Shanghai, People's Republic of China
Correspondence: Junbo Ge Department of Cardiology, Shanghai Institute of Cardiovascular Diseases, Zhongshan Hospital, Fudan University, 180 Fenglin Road, Shanghai 200032, People's Republic of China

Tel +862 2l 64041909 ext 2745

Email ge.junbo@zs-hospital.sh.cn

\begin{abstract}
Coronary heart disease (CHD) is the leading cause of death worldwide. The efficacy and safety of statins in primary and secondary prevention of CHD is confirmed in several large studies, and rosuvastatin is the latest statin on market. We review the published literature on rosuvastatin in Chinese people. The pharmacokinetics of rosuvastatin in Chinese is somewhat different from that in Caucasians, but this does not influence the linear relationship between dosage and efficacy and with no drug accumulation. Rosuvastatin $5-20 \mathrm{mg}$ /day is effective and safe in decreasing low-density lipoprotein cholesterol in both younger and elderly patients with hypercholesterolemia, even in very elderly patients. Rosuvastatin also shows anti-inflammatory and antiatherosclerosis features, such as reducing carotid intima-media thickness and plaque area. Rosuvastatin can also improve the prognosis of Chinese CHD patients, such as in the case of acute myocardial infarction. Its adverse-event rate is low and comparable to other statins. In conclusion, rosuvastatin is effective and safe for younger or elderly Chinese patients.
\end{abstract}

Keywords: rosuvastatin, Chinese, younger, elderly

\section{Introduction}

Coronary heart disease (CHD) has been the leading cause of death for the last 10 years, as announced by the World Health Organization, ${ }^{1}$ accounting for $11.24 \%$ of all deaths in 2011. Its primary and secondary prevention is of great importance. Low-density lipoprotein cholesterol (LDL-C) is an established risk factor of CHD. The efficacy and safety of statins, which decrease the level of LDL-C, is confirmed in the treatment of CHD. Rosuvastatin is a relatively new statin, though it has been reported in many clinical trials ${ }^{2}$ to reduce LDL-C more aggressively without increasing complications and improve prognosis.

Rosuvastatin shares the mechanism of action of the statin class; however, it is one of the most potent inhibitors of 3-hydroxy-3-methylglutaryl coenzyme A reductase activity. Rosuvastatin has been studied in clinical trials involving $>46,000$ patients. The results of the GALAXY program of randomized clinical trials have shown its efficacy and safety in patients with a broad range of demographic and clinical characteristics, including younger and elderly patients, men and women, and accompanied by other risk factors or diseases.

The People's Republic of China is a developing country; however, the prevalence of CHD is increasing with Westernized lifestyle and stress. Rosuvastatin is the latest statin on the Chinese market. Though it has been widely evaluated in clinical trials, mostly in Caucasians, drugs may act differently between ethnicities. We intend to 
review the literature on rosuvastatin in Chinese patients and to evaluate the efficacy and safety of rosuvastatin in Chinese adults, both young and elderly, in managing hyperlipidemia and preventing cardiovascular events.

\section{Pharmacokinetics of rosuvastatin in Chinese adults}

Pharmacokinetic trials have often been undertaken with young healthy volunteers. Trials showed that rosuvastatin nearly fits a linear dynamic feature at a dosage of 5-20 mg in the Chinese. ${ }^{3-6}$ In one trial, geometric mean maximum concentration $\left(\mathrm{C}_{\max }\right)$ values for rosuvastatin after administration of single doses of rosuvastatin 5, 10, and $20 \mathrm{mg}$ were $8.33,10.76$, and $19.17 \mathrm{ng} / \mathrm{mL}$, respectively; the corresponding geometric mean area under the curve $\left(\mathrm{AUC}_{0-\mathrm{t}}\right)$ values were $57.63,88.89$, and $163.87 \mathrm{ng} /$ hour $/ \mathrm{mL}$. In the steady state, values for $\mathrm{C}_{\max }$ were $8.31,8.41$, and $20.73 \mathrm{ng} / \mathrm{mL}$; the corresponding geometric mean AUC values were 64.87, 77.29, and $178.64 \mathrm{ng} /$ hour$/ \mathrm{mL} .^{6}$

After multiple oral doses of 5, 10, and $20 \mathrm{mg}$ rosuvastatin once daily for 8 days, there was little drug accumulation in healthy Chinese volunteers. ${ }^{4}$ In another study, the accumulation ratios at 5,10 , and $20 \mathrm{mg}$ were $1.23,0.95$, and 1.23, respectively. ${ }^{6}$ The DISCOVERY (Direct Statin Comparison of LDL-C Values: an Evaluation of Rosuvastatin Therapy)-Asia study included a substantial number of patients from the People's Republic of China and did not show any obvious difference in their lipid response to other studies with the same dose of rosuvastatin. ${ }^{7}$ However, The LDL-C response to rosuvastatin in DISCOVERY-Hong Kong statin-naive patients $(-52.8 \%)$ was greater, and was still significant after adjustment for multiple testing. ${ }^{8}$ Another trial also suggested that rosuvastatin had a higher absorption rate in Asian people. There was a remarkable ethnic difference in pharmacokinetic profiles between Chinese and Caucasians in younger adults, with twice the $\mathrm{AUC}$ and $\mathrm{C}_{\max }$ in Chinese and similar time to $\mathrm{C}_{\max }$ and half-life. ${ }^{9}$ The difference might be explained by genetic determinants, such as the adenosine triphosphate-binding cassette G2 polymorphism. ${ }^{10,11}$ However, there was no significant difference of the dosage and efficiency curve between Western and Chinese people. ${ }^{12}$

\section{Rosuvastatin in hyperlipidemia}

Rosuvastatin $40 \mathrm{mg}$ is not available on the Chinese market. The common dosage is $5-20 \mathrm{mg} /$ day in clinical practice, with $5 \mathrm{mg} /$ day as the initial dose and $10 \mathrm{mg} /$ day as normal dosage.

\section{Younger patients}

Some relatively large randomized control trials $\mathrm{s}^{7,13-15}$ have been undertaken in Chinese people; inclusion age was 18-75 years. Most patients enrolled in trials were younger people. Rosuvastatin showed its efficacy and safety in younger patients.

The Chinese Rosuvastatin Registry trial was designed to evaluate the efficacy and safety of rosuvastatin in treating Chinese patients with hypercholesterolemia. This was a randomized double-blind multicenter study in ten top-level hospitals in Shanghai, Beijing, Changsha, and Chengdu. From March 2004 to April 2005, it enrolled 304 patients (both younger and elderly, range $18-75$ years old, mostly young patients, with mean age $57.9 \pm 9.2$ years and $27.2 \%$ male) with LDL-C $\geq 160 \mathrm{mg} / \mathrm{dL}$ but $<250 \mathrm{mg} / \mathrm{dL}$, and triglycerides $(\mathrm{TG})<400 \mathrm{mg} / \mathrm{dL}$ in a 2:1 ratio, receiving rosuvastatin $10 \mathrm{mg} /$ day (R group) and atorvastatin $10 \mathrm{mg} /$ day (A group) for 12 weeks. LDL-C decreased more in the R group than the A group (45.6\% versus (vs) $39.0 \%, P<0.001$ ). The percentage reaching the National Cholesterol Education Program Adult Treatment Panel III target in the R group tended to be higher than in the A group (78.0\% vs $72.7 \%$ ), especially in high risk patients $(56.5 \%$ vs $35 \%)$. There were no drug related serious adverse events found during the study. It showed the efficacy of rosuvastatin of reducing LDL-C was better than atorvastatin at the same dose in Chinese people, with a similar safety profile. ${ }^{13}$

Two trials were designed to compare the efficacy and safety of rosuvastatin at low and standard doses to atorvastatin. A double-blind randomized multicenter clinical trial was conducted for treatment of 341 patients with hypercholesterolemia in five hospitals in central China from November 2005 to November 2006. Patients were randomized into three groups, receiving rosuvastatin $(5 \mathrm{mg} /$ day, $\mathrm{n}=113 ; 10 \mathrm{mg} /$ day, $\mathrm{n}=114)$ or receiving atorvastatin $10 \mathrm{mg} /$ day $(\mathrm{n}=114$, control group) for 8 weeks. The mean age was $52.87 \pm 10.07$ years. Compared to baseline, LDL-C decreased $42.41 \%$, 44.88\%, and $39.65 \%$ in the low- and high-dose rosuvastatin groups and atorvastatin group, respectively. Rosuvastatin was not inferior to atorvastatin, and rosuvastatin $10 \mathrm{mg}$ was better than atorvastatin $10 \mathrm{mg} .{ }^{14}$

Another similar randomized double-blind multicenter controlled trial was conducted. The eligible 315 patients with primary hypercholesterolemia were randomized 1:1:1 for rosuvastatin $10 \mathrm{mg} /$ day $(\mathrm{n}=110)$, rosuvastatin $5 \mathrm{mg} /$ day $(\mathrm{n}=101)$, and atorvastatin $10 \mathrm{mg} /$ day $(\mathrm{n}=104)$. The mean age was $54.95 \pm 10.68$ years. After 8 weeks' treatment, LDL-C decreased significantly in both rosuvastatin groups versus the 
atorvastatin group ( $-43.6 \%$ and $-42.5 \%$ vs $-36.5 \%$, for 10 and $5 \mathrm{mg} /$ day rosuvastatin, and atorvastatin, respectively; both $P<0.05) .{ }^{15}$ There were no drug-related adverse reactions found during the study in either trial.

The DISCOVERY-Asia study was a 12-week, randomized, open-label, parallel-group study conducted in the People's Republic of China, Hong Kong, South Korea, Malaysia, Taiwan, and Thailand. A total of 1,482 adults with primary hypercholesterolemia and high cardiovascular risk were randomized in a $2: 1$ ratio to receive rosuvastatin $10 \mathrm{mg} /$ day or atorvastatin $10 \mathrm{mg} /$ day. The mean age was about 60 years. This study showed that rosuvastatin $10 \mathrm{mg} /$ day was significantly more effective than atorvastatin $10 \mathrm{mg} /$ day at enabling patients with primary hypercholesterolemia to achieve European goals for LDL-C and total cholesterol (TC) in an Asian population in real-life clinical practice. The safety profile of rosuvastatin $10 \mathrm{mg}$ was similar to that of atorvastatin $10 \mathrm{mg}$ in the Asian population studied here, and was consistent with the known safety profile of rosuvastatin in the white population. In this study, $40.8 \%$ of the patients were Chinese, with 404 cases of rosuvastatin and 199 cases of atorvastatin; this could indicate the efficacy and safety of rosuvastatin in Chinese patients. ${ }^{7}$

\section{Elderly patients}

The prevalence of CHD is highest in persons aged $>65$ years, and most coronary events and consequent deaths occur in this age-group. The cumulative effects of lifetime exposure to such risk factors as dyslipidemia, diabetes mellitus, and cigarette smoking may contribute to an increased risk in the elderly population. Among the statins, rosuvastatin may have some advantages in treating older patients: at a low starting dosage, it is efficacious compared with other statins, and thus more likely to reach the LDL-C goal without the need for high-dose titration and/or combination therapy. Also, it is not metabolized by cytochrome P450 enzyme 3A4, making rosuvastatin safer for elderly patients who usually take multiple medications.

Clinical trials of statins, including rosuvastatin, over the last three decades have not included large numbers of elderly patients. ${ }^{16}$ However, subgroup analyses of many of these trials have shown that aggressive lipid-lowering treatment with statins in elderly patients reduced absolute risk as much as in younger patients, markedly decreasing the incidence of fatal and nonfatal coronary events in persons with and without advanced atherosclerotic lesions and cardiovascular disease.

Some small trials have been undertaken in elderly Chinese people (defined as older than 65 years) in clinical trials. In elderly patients, drug safety is always a concern. Regarding the slow metabolism and risk of accumulation of drugs, a low dosage of rosuvastatin $5 \mathrm{mg}$ /day was preferred in elderly patients, if their LDL-C level was not very high. A study ${ }^{17}$ has shown that even the low dose of $5 \mathrm{mg}$ rosuvastatin was effective in elderly patients, compared to other statins.

In one of these studies, a randomized double-blind trial enrolled, 126 patients from January to August 2008 were divided into two groups. All of the patients were male and older than 70 years; the mean age was $78.6 \pm 8.3$ years. The treatment group (63 cases) was treated with rosuvastatin $5 \mathrm{mg} /$ day, and the control group (63 cases) with simvastatin $10 \mathrm{mg} /$ day. The course of the treatment continued for 8 weeks. TC, LDL-C, and TG were reduced by $27.5 \%, 36.6 \%$, and $12.7 \%$, respectively, in the rosuvastatin group after 8 weeks' treatment, and $27.4 \%, 33.6 \%$, and $12.5 \%$ in the simvastatin group $(P>0.05)$. All of the patients had good compliance and tolerance to the two drugs during the trial. No serious adverse events related to drugs were observed. ${ }^{17}$

For the standard dosage of rosuvastatin $10 \mathrm{mg} /$ day, some small randomized controlled studies showed it could reduce LDL-C effectively, and it was at least as good as or even better than simvastatin 10-20 mg and atorvastatin $20 \mathrm{mg}$ in elderly patients. ${ }^{18-20}$

One trial compared rosuvastatin $10 \mathrm{mg}$ /day to simvastatin $10 \mathrm{mg}$ /day. A total of 118 patients with hypercholesterolemia who were treated in one hospital from March 2009 to June 2012 were randomly divided into control group and study group. Age-range was 72-85 years, and the mean age was $76.24 \pm 3.68$ years, with males comprising $51.7 \%$. The inclusion criteria were LDL-C 4.14-6.60 mmol/L and $\mathrm{TG}<4.52 \mathrm{mmol} / \mathrm{L}$. The study lasted for 4 weeks. After treatment, compared with the simvastatin group, LDL-C target levels in the rosuvastatin group decreased to a significantly greater extent $(3.38 \pm 1.06 \mathrm{mmol} / \mathrm{L}$ to $3.41 \pm 1.21 \mathrm{mmol} / \mathrm{L}$ in the rosuvastatin group, and $2.36 \pm 0.62 \mathrm{mmol} / \mathrm{L}$ to $2.02 \pm 0.74 \mathrm{mmol} / \mathrm{L}$ in the simvastatin group; $P<0.05)$. However, there was no significant difference in TG or highdensity lipoprotein cholesterol (HDL-C) levels between the two groups $(P>0.05)$. There were no serious adverse events involving liver, muscle, or kidney. ${ }^{18}$

Rosuvastatin $10 \mathrm{mg}$ /day was also compared to simvastatin $20 \mathrm{mg} /$ day. In one small trial, the selected patients were randomly divided into the rosuvastatin group $(n=44$, rosuvastatin $10 \mathrm{mg}$ every night) and the simvastatin group ( $n=43$, simvastatin $20 \mathrm{mg}$ every night). After treatment of 8 weeks, the decrease of LDL-C in the rosuvastatin group was significantly greater than that of the simvastatin group 
(43.2\% vs $35.3 \%, P<0.05)$. The control rate of LDL-C in the rosuvastatin group was higher than that in the simvastatin group ( $85.1 \%$ vs $59.8 \%, P<0.05)$. The rate of HDL-C increase in the rosuvastatin group was significantly greater than that in the simvastatin group $(6.5 \%$ vs $1.6 \%, P<0.05)$. The rates of TC and TG decrease in the rosuvastatin group were slightly better than those in the simvastatin group $(32.2 \%$ vs $30.8 \%$ and $17.0 \%$ vs $15.2 \%$, respectively; $P>0.05) .{ }^{19}$

Another trial compared rosuvastatin $10 \mathrm{mg} /$ day to atorvastatin, which was more potent than simvastatin, with a standard dosage of $20 \mathrm{mg} /$ day. After a 4-week dietary run-in period, a single-blind randomized control trial was conducted in 67 aged patients with LDL-C levels $\geq 4.14$ and $\leq 6.50 \mathrm{mmol} / \mathrm{L}$ and $\mathrm{TG}$ levels $\leq 4.52 \mathrm{mmol} / \mathrm{L}$, who were randomized into a rosuvastatin $10 \mathrm{mg}$ group ( $\mathrm{R}$ group, $\mathrm{n}=33$ ) and an atorvastatin $20 \mathrm{mg}$ group (A group, $\mathrm{n}=34$ ) for 4 weeks. Rosuvastatin $10 \mathrm{mg} /$ day was more effective than atorvastatin $20 \mathrm{mg} /$ day (LDL-C level changed from $3.4 \pm 0.9 \mathrm{mmol} / \mathrm{L}$ to $2.8 \pm 0.8 \mathrm{mmol} / \mathrm{L}$ in the $\mathrm{R}$ group and $3.3 \pm 1.2 \mathrm{mmol} / \mathrm{L}$ to $2.4 \pm 0.7 \mathrm{mmol} / \mathrm{L}$ in the A group, and TC level from $5.5 \pm 1.1 \mathrm{mmol} / \mathrm{L}$ to $4.84 \pm 0.9 \mathrm{mmol} / \mathrm{L}$ in the $\mathrm{R}$ group and $5.2 \pm 1.2 \mathrm{mmol} / \mathrm{L}$ to $4.5 \pm 0.6 \mathrm{mmol} / \mathrm{L}$ in the A group; both $P<0.05)$. There was no significant safety-data difference between the two groups. No drug-related serious adverse events were found during the study. ${ }^{20}$

\section{Very elderly patients}

Very elderly people ( $>80$ years old) are always the most special age group, with reduced organ function, especially liver and renal function, multiple medications, and high morbidity. Thus, the safety of a drug is of great concern, as is its efficacy. However, very elderly patients are not always enrolled in large randomized clinical trials. Meanwhile, they are always at high risk of cardiovascular events, and thus statins are still needed in this group of patients.

Some small observational trials have been undertaken in very elderly Chinese patients. Although the studies were quite small, they still gave us some information on these fragile patients. Results showed that in very old hyperlipidemia or CHD patients, rosuvastatin was also effective and safe. In a series of small single-center trials, rosuvastatin $10 \mathrm{mg}$ reduced LDL-C by $29.6 \%-45.5 \%$ in 12 weeks. ${ }^{21-23}$ There were no obvious major adverse events.

In one observational single-center trial, 45 patients were enrolled (42 male and three female, mean age 83.5 years). The patients received rosuvastatin $10 \mathrm{mg} /$ day for 12 weeks. Rosuvastatin reduced TC $(5.80 \pm 0.56 \mathrm{mmol} / \mathrm{L}$ to $4.02 \pm 0.46 \mathrm{mmol} / \mathrm{L})$ and LDL-C $(3.26 \pm 0.85 \mathrm{mmol} / \mathrm{L}$ to
$1.96 \pm 0.67 \mathrm{mmol} / \mathrm{L})$ effectively, and also increased HDL-C $(1.20 \pm 0.21 \mathrm{mmol} / \mathrm{L}$ to $1.48 \pm 0.31 \mathrm{mmol} / \mathrm{L})$, all $P<0.05$. Three patients suffered from mild abdomen discomfort and two patients felt nausea, but no patient discontinued treatment. Creatinine, alanine transaminase (ALT), and aspartate transaminase (AST) levels showed no change after treatment. ${ }^{21}$

Another trial showed that the efficacy of rosuvastatin $10 \mathrm{mg}$ /day was observed as early as 2 weeks and continued to reduce lipids until 12 weeks. The trial enrolled a total of 62 very old patients $(80-87$ years old, mean age $82.2 \pm 3.2$ years) with hypercholesterolemia, who received rosuvastatin $10 \mathrm{mg} /$ day. The changes in TC, TG, LDL-C, HDL-C, ALT, AST, creatine kinase (CK), and creatinine were compared before and after treatment. After 2 weeks' treatment with rosuvastatin, levels of TC (from $6.39 \pm 1.10 \mathrm{mmol} / \mathrm{L}$ to $5.58 \pm 1.11 \mathrm{mmol} / \mathrm{L}$ ) and LDL-C (from $4.22 \pm 0.91 \mathrm{mmol} / \mathrm{L}$ to $3.12 \pm 0.87 \mathrm{mmol} / \mathrm{L}$ ) significantly decreased; after 12 weeks' treatment with rosuvastatin, levels of TC $(6.39 \pm 1.10$ to $4.59 \pm 0.99 \mathrm{mmol} / \mathrm{L})$ and LDL-C $(4.22 \pm 0.91 \mathrm{mmol} / \mathrm{L}$ to $2.30 \pm 0.78 \mathrm{mmol} / \mathrm{L}$ ) decreased more remarkably (all $P<0.05)$. All patients showed good compliance and tolerance with rosuvastatin $10 \mathrm{mg} /$ day. No adverse drug reaction was observed. ${ }^{22}$

One trial also compared rosuvastatin with simvastatin and atorvastatin in very elderly patients. The trial enrolled a selected 73 cases over 80 years old $(81.7 \pm 2.1$ years $)$, (80-86 years) with CHD, who were divided into three groups according to the different statin drugs: 27 in the simvastatin group ( $20 \mathrm{mg} /$ day), 32 in the atorvastatin group ( $20 \mathrm{mg} /$ day), and 14 in the rosuvastatin group ( $5 \mathrm{mg}$ /day). Blood lipid parameters and safety indicators were monitored before treatment and at follow up at 12-24 (mean $13.8 \pm 3.7$ ) months in all the patients. Results showed that the low dose of rosuvastatin $5 \mathrm{mg} /$ day was as effective and safe as the standard dosage of simvastatin and atorvastatin. The reduction of TC and LDL-C was obvious after treatment of $5 \mathrm{mg} /$ day rosuvastatin $(3.59 \pm 0.67 \mathrm{mmol} / \mathrm{L}$ to $3.84 \pm 0.91 \mathrm{mmol} / \mathrm{L}$, and $2.16 \pm 0.61 \mathrm{mmol} / \mathrm{L}$ to $2.39 \pm 0.78 \mathrm{mmol} / \mathrm{L}$; both $P<0.05)$. There were few adverse events after treatment. Blood lipid parameters and safety profiles after treatment in the simvastatin group, atorvastatin group, and low-dose rosuvastatin group were not significantly different, including CK and liver and renal function. ${ }^{23}$

\section{Effect of rosuvastatin on atherosclerosis}

Carotid intima-media thickness (IMT) is a marker of atherosclerosis that is a widely used surrogate end point of the 
effectiveness of statins on atherosclerosis. It is a noninvasive measurement, and can be easily assessed.

Rosuvastatin is an aggressive lipid-lowering drug; it has been confirmed in small trials to be effective in treating carotid atherosclerosis in Chinese patients with or without hyperlipidemia. ${ }^{24,25}$ It also has anti-inflammatory and antiatherosclerosis effects in many kinds of patients, eg, those with hyperlipidemia, acute coronary syndrome, or hypertension. The effect is dose-dependent, and there are no serious adverse events, even at $20 \mathrm{mg} /$ day. ${ }^{26}$

One controlled trial enrolled 40 patients with carotid plaque receiving rosuvastatin $10 \mathrm{mg}$ and placebo for 12 months. Total plaque numbers showed no significant change in either group, while plaque thickness reduced significantly from $1.92 \pm 0.53 \mathrm{~mm}$ to $1.10 \pm 0.50 \mathrm{~mm}(P<0.05)$ in the rosuvastatin group, and $74.5 \%$ of soft plaques changed into hard plaques. Meanwhile, plaque thickness increased from $1.60 \pm 0.37 \mathrm{~mm}$ to $1.72 \pm 0.38 \mathrm{~mm}$, and $15.7 \%$ of soft plaques changed into hard plaques in the control group. ${ }^{27}$

Another trial enrolled 70 acute coronary syndrome patients (male 55, female 15, age 45-78 years, mean age $59 \pm 11.2$ years). There were 13 cases of acute myocardial infarction, and 57 cases of unstable angina. The patients also had documented carotid atherosclerosis plaque without statin therapy in the last few months. The patients were given rosuvastatin $10 \mathrm{mg}$ per night for 6 months. The result of the study showed that rosuvastatin $10 \mathrm{mg}$ was observed to stabilized plaque, significantly reducing IMT and carotid plaque areas $(1.58 \pm 0.37 \mathrm{~mm}$ to $1.42 \pm 0.34 \mathrm{~mm}$ and $0.86 \pm 0.17$ to $0.47 \pm 0.19 \mathrm{~cm}^{2}$ ), accompanied by significant decreases in serum level of TC, LDL-C, and high-sensitivity C-reactive protein (hs-CRP) $(18.71 \pm 2.15 \mathrm{mg} / \mathrm{L}$ to $6.78 \pm 2.07 \mathrm{mg} / \mathrm{L}$, all $P<0.01){ }^{28}$

One study showed rosuvastatin on the basis of conventional antihypertensive drug treatment produced significant reduction of the levels of microalbuminuria, IMT, and coronary calcium score (CS) in patients with essential hypertension. A total of 76 hypertensive patients were randomly selected to receive conventional antihypertensive drugs (amlodipine $5 \mathrm{mg} /$ day and telmisartan $80 \mathrm{mg} /$ day, $\mathrm{n}=37$, mean age $61.7 \pm 8.4$ years) or rosuvastatin ( $10 \mathrm{mg}$ every night) on the top of conventional antihypertensive drugs $(n=39$, mean age $60.9 \pm 9.2$ years). Blood pressure, levels of microalbuminuria, echocardiography and helical computerized tomography were examined. After 8 months of treatment, combined treatment significantly reduced the levels of microalbuminuria (31.6 \pm 21.8 to $23.2 \pm 19.8 \mathrm{mg} / \mathrm{g}, P<0.01)$, IMT of the common carotid artery, and CS (IMT from $0.95 \pm 0.32$ to
$0.84 \pm 0.28 \mathrm{~mm}, \mathrm{CS}$ from $2.35 \pm 2.13$ to $1.71 \pm 1.68$; both $P<0.01)$. No effect on levels of microalbuminuria, IMT, or CS by conventional antihypertensive drugs was found. ${ }^{29}$

Rosuvastatin can improve endothelial function as well as reduce IMT. One trial showed rosuvastatin increased endothelium-dependent flow-mediated dilation (EDFMD) significantly. A total of 110 hypercholesterolemic patients (male 47, female 63, age 18-70 years, mean age $56.5 \pm 10.3$ years) were randomly divided into three groups: the rosuvastatin $10 \mathrm{mg}$ group ( $n=36)$, the atorvastatin $10 \mathrm{mg}$ group $(n=38)$, and the diet-therapy group $(n=36)$. The control group comprised 30 healthy volunteers. Before treatment, IMT in patients of the rosuvastatin group, atorvastatin group, and diet therapy group was significantly higher than that of healthy subjects $(P=0.029)$, and EDFMD was significantly lower than that of healthy subjects $(P=0.014)$. After 8 weeks of rosuvastatin and atorvastatin treatment, IMT decreased significantly $(P<0.05)$ and EDFMD increased significantly $(P<0.05)$. However, after 8 weeks of diet treatment, IMT and EDFMD did not change obviously $(P \geq 0.05){ }^{24}$

\section{Rosuvastatin and clinical prognosis}

Rosuvastatin can improve the prognosis of Chinese patients with acute myocardial infarction, by lowering blood lipids, reducing inflammatory response, and improving endothelial function. It is as good as or better than other statins, such as atorvastatin or simvastatin. ${ }^{30-32}$

A prospective randomized controlled trial compared rosuvastatin and atorvastatin on 102 acute myocardial infarction patients. Rosuvastatin $10 \mathrm{mg} /$ day $(\mathrm{n}=51$, mean age $49.65 \pm 5.6$ years) and atorvastatin $20 \mathrm{mg} /$ day $(\mathrm{n}=51$, mean age $50.32 \pm 6.1$ years) were given to patients for 6 months. After treatment, TC and hs-CRP levels were significantly more reduced in the rosuvastatin group than the atorvastatin group (hs-CRP $14.6 \pm 0.95$ to $1.84 \pm 0.32 \mathrm{mg} / \mathrm{L}$ vs $14.21 \pm 1.29$ to $2.27 \pm 0.62 \mathrm{mg} / \mathrm{L}, P<0.05)$. In both groups, flow-mediated dilation improved compared to baseline, but there was no significant difference between rosuvastatin and atorvastatin. No serious cardiovascular events happened in either group, including death and nonfatal myocardial infarction. The recurrent angina and revascularization rates were lower in the rosuvastatin group than in the atorvastatin group (3.9\% vs $7.8 \%$ and $5.9 \%$ vs $9.8 \%$, respectively). ${ }^{30}$

Another trial enrolled 74 younger patients (males $\leq 55$ years old, females $\leq 65$ years old, mean age $52.3 \pm 6.2$ years) with premature acute myocardial infarction after successful percutaneous coronary intervention (PCI), randomly divided into rosuvastatin $10 \mathrm{mg} /$ day $(\mathrm{n}=38)$ or atorvastatin 
$20 \mathrm{mg} /$ day $(\mathrm{n}=36)$ groups. After 6 months, the levels of hs-CRP decreased significantly more in the rosuvastatin group than in the atorvastatin group $(14.35 \pm 1.95$ to $1.94 \pm 0.56 \mathrm{mg} / \mathrm{L}$ and $13.43 \pm 2.24$ to $2.37 \pm 0.64 \mathrm{mg} / \mathrm{L}$, respectively; $P<0.05)$, and the change of flow-mediated dilation (FMD) improved, compared to baseline $(6.31 \pm 2.03 \%$ to $7.87 \pm 1.45 \%$, and $6.28 \pm 2.14 \%$ to $7.95 \pm 1.20 \% ; P<0.05)$. The two groups showed no significant difference in terms of major adverse cardiovascular events (MACEs). There were no deaths in either group, the angina rate was $5.3 \%$ and $8.3 \%$, and the revascularization rate was $8.3 \%$ and $2.8 \%$ in the rosuvastatin group and the atorvastatin group, respectively (both $P>0.05) .{ }^{31}$

Rosuvastatin therapy in addition to conventional medications could improve the functions of the surviving myocardium in patients with ST-elevation acute myocardial infarction (STEMI) after PCI, assessing by ${ }^{99 \mathrm{~m}} \mathrm{TC}$ methoxyisobutylisonitrile (MIBI) uptake fraction. A total of 65 STEMI patients were randomized to receive $40 \mathrm{mg}$ simvastatin $(n=32)$ or $10 \mathrm{mg}$ rosuvastatin $(n=33)$ in addition to conventional medications. At the end of 12 months, the patients in the simvastatin group showed significantly reduced TC, LDL-C, CRP, tumor necrosis factor (TNF)- $\alpha$, and ${ }^{99 \mathrm{~m}}$ TC-MIBI uptake fraction improved in both groups, and was more effective in the rosuvastatin group: hsCRP reduced from $0.67 \pm 0.25$ to $0.41 \pm 0.15 \mathrm{mg} / \mathrm{mL}$ with simvastatin, and $0.73 \pm 0.21$ to $0.28 \pm 0.13 \mathrm{mg} / \mathrm{mL}$ with rosuvastatin; and TNF- $\alpha 2.33 \pm 1.47$ to $1.48 \pm 1.15 \mathrm{ng} / \mathrm{mL}$ and $2.28 \pm 1.54$ to $1.05 \pm 0.9 \mathrm{ng} / \mathrm{mL}$, respectively. The ${ }^{99 \mathrm{~m}}$ TC-MIBI uptake fraction increased in both groups, but had more increment in rosuvastatin group $(0.81 \pm 0.18 \mathrm{vs}$ $0.43 \pm 0.09, P<0.05)$. The IMT of the common carotid artery was reduced significantly after 12-month rosuvastatin therapy, but remained almost unchanged after simvastatin therapy. ${ }^{32}$

Upstream high-dose statins before coronary intervention have been proven to have a protective effect. This was also evaluated in a small group of Chinese patients with rosuvastatin. ${ }^{33}$ The trial showed that early administration of high-dose rosuvastatin (40 mg) could improve coronary microvascular function and short-term outcome in patients treated with PCI for acute myocardial infarction, and it was efficacious and safe. Consequently, 86 acute myocardial infarction patients (onset within 12 hours) treated with primary PCI were divided into a study group ( $n=46$, rosuvastatin $40 \mathrm{mg}$ before primary PCI and $10 \mathrm{mg} /$ day after procedure) and a control group $(n=40$, only rosuvastatin $10 \mathrm{mg} /$ day after procedure). MACEs were defined as a composite of cardiovascular death, nonfatal myocardial infarction, recurrent angina, or heart failure. Myocardial and microvascular perfusion was assessed using the Thrombolysis in Myocardial Infarction (TIMI) myocardial perfusion grade (TMPG). The follow-up time was 30 days. Both the study group and control group showed better TMPG immediately after PCI $(P<0.05)$. However, the post-PCI TMPG of the study group was much better than that of the control group $(P=0.039)$. Compared with the control group, the 30-day composite MACE rate was lower in the study group, both for all the patients $(13.0 \%$ vs $32.5 \%, P<0.05)$ and for the TMPG 3 patients $(42.9 \%$ vs $11.1 \%, P=0.029)$. Moreover, the relative risk of MACEs for patients in the control group was 3.857 (95\% confidence interval 1.131-13.149) compared with patients in the study group. There was no cytotoxicity and hepatotoxicity in either group. ${ }^{33}$

\section{Safety of rosuvastatin}

In elderly patients especially, the tolerance of a drug may be as important as its efficacy. The safety and tolerability of rosuvastatin were assessed using data from 16,876 patients who received rosuvastatin $5-40 \mathrm{mg} /$ day in a multinational Phase II/III/IIIb/IV program. Occurrence and types of adverse events irrespective of causality did not differ according to age.

Because of the high prevalence of hepatitis in the People's Republic of China, the influence of statins on liver function is always the first concern. All statins may slightly induce elevation of liver enzymes, and it is usually transient and reversible with dose reduction or discontinuation. Although rosuvastatin is more aggressive than other statins, comparison of rates of transaminase elevation between rosuvastatin and atorvastatin or simvastatin show little difference. ${ }^{34}$ Also, in the rosuvastatin clinical database, elevations in hepatic transaminases of three times the upper limit of normal occurred in only $0.2 \%$ of rosuvastatin recipients at up to the maximum dose. ${ }^{35}$

Concerns have been raised about an increased incidence of proteinuria with rosuvastatin. In clinical trials, the rate of proteinuria is $<1 \%-1.2 \%$, at dosages of $5-40 \mathrm{mg} /$ day. Proteinuria was usually not associated with evidence of decreasing renal function. ${ }^{34}$

Last but not least, myopathy is still very important. In the rosuvastatin clinical database, the rate of myopathy is $\leq 0.03 \%$ for those receiving rosuvastatin $10-40 \mathrm{mg} / \mathrm{day}$, lower than that of the other statins. ${ }^{35}$

As mentioned earlier, the pharmacokinetics of rosuvastatin are somewhat different between Chinese and Caucasians, 
but dosage and concentration still show linear characteristics and no accumulation. The Chinese studies of rosuvastatin always monitored liver, kidney and muscle damage markers, such as ALT, AST, serum creatinine, and CK.

The Chinese Rosuvastatin Registry trial showed a low rate of elevation of liver enzymes and $\mathrm{CK}$ in the rosuvastatin $10 \mathrm{mg}$ group, and there were no differences from the atorvastatin $10 \mathrm{mg}$ group ( $3.0 \%$ vs $1.0 \%$, and $1.0 \%$ vs $1.9 \%$, respectively; $P>0.05$ ). No patient was found with $\mathrm{CK}$ elevated above five times the upper limit. Only one patient with rosuvastatin had liver enzymes elevated above three times the upper limit, and recovered in 1 month after discontinuing the drug. ${ }^{13}$

In other studies, as described earlier, there were no obvious side effects of rosuvastatin 5-20 mg on liver, kidney, or muscle. Nor was there any significant difference compared to different dosage of atorvastatin and simvastatin. Thus, rosuvastatin $5-20 \mathrm{mg}$ is safe in Chinese patients, both younger ( $<65$ years old) and elderly ( $>65$ years old).

\section{Limitations}

Rosuvastatin has already been widely evaluated in several large studies worldwide, and has established an important role in cardiovascular diseases. Rosuvastatin is the latest statin available on market. Because of the short marketing history in the People's Republic of China, there has been no large randomized controlled trial undertaken in Chinese people. Some trials have been single-center or observational studies or with rather small patient samples, and thus not powerful enough to reach a conclusion. However, these studies can still give some information on rosuvastatin in clinical practice in real life in the People's Republic of China. The data shown in this review support the efficacy and safety of rosuvastatin $5-20 \mathrm{mg} /$ day in Chinese patients, both younger $(<65$ years old) and elderly ( $>65$ years old).

\section{Disclosure}

The authors report no conflicts of interest in this work.

\section{References}

1. World Health Organization. The top 10 caused of death. World Health Organizaion, 2013. Available from: http://www.who.int/mediacentre/ factsheets/fs310/en/. Accessed November 6, 2013.

2. Nicholls SJ, Brandrup-Wognsen G, Palmer M, Barter PJ. Meta-analysis of comparative efficacy of increasing dose of Atorvastatin versus Rosuvastatin versus Simvastatin on lowering levels of atherogenic lipids (from VOYAGER). Am J Cardiol. 2010 ;105(1):69-76.

3. Zhang H, Xiong YQ. Pharmacokinetics of rosuvastatin calcium tablets in Chinese healthy volunteers after a single oral dose administration. Zhongguo Lin Chuang Yao Li Xue Za Zhi. 2007;23(4):268-273.

4. Zhang H, Xiong YQ. Pharmacokinetics of multiple oral doses of rosuvastatin calcium tablets. Chung Kuo Yao Hsueh Tsa Chih. 2007;42(23): 1818-1823.
5. Lee E, Ryan S, Birmingham B, et al. Rosuvastatin pharmacokinetics and pharmacogenetics in white and Asian subjects residing in the same environment. Clin Pharmacol Ther. 2005;78(4):330-341.

6. Li XN, Xu HR, Chen WL, Chu NN, Zhu JR. Pharmacokinetics of rosuvastatin in healthy Chinese volunteers living in China: a randomized, open-label, ascending single- and multiple-dose study. Clin Ther. 2010;32(3):575-587.

7. Zhu JR, Tomlinson B, Ro YM, Sim KH, Lee YT, Sriratanasathavorn C. A randomised study comparing the efficacy and safety of rosuvastatin with atorvastatin for achieving lipid goals in clinical practice in Asian patients at high risk of cardiovascular disease (DISCOVERY-Asia study). Curr Med Res Opin. 2007;23(12):3055-3068.

8. Hu M, Lui SS, Ko GT, Tomlinson B. Do the lipid responses to rosuvastatin and atorvastatin differ between Chinese and Caucasians? Comparison of the DISCOVERY-Hong Kong study with other DISCOVERY studies. Int J Cardiol. Epub May 1, 2013.

9. Jiang JJ, Tian L, Huang YL. Study on pharmacokinetics of rosuvastatin calcium tablets in Chinese healthy subjects. Chin J Hosp Pharm. 2007;27(11):1497-1502.

10. Tomlinson B, Hu M, Lee VW, et al. ABCG2 polymorphism is associated with the low-density lipoprotein cholesterol response to rosuvastatin. Clin Pharmacol Ther. 2010;87(5):558-562.

11. Lee HK, Hu M, Lui SS, Ho CS, Wong CK, Tomlinson B. Effects of polymorphisms in ABCG2, SLCO1B1, SLC10A1 and CYP2C9/19 on plasma concentrations of rosuvastatin and lipid response in Chinese patients. Pharmacogenomics. 2013;14(11):1283-1294.

12. Ang J, Li LJ, He YC, Xu L, Lv YH, Zhang M. An exploring study on the pharmacodynamics of rosuvastatin in Chinese hypercholesterolemic patients. Chin J Clin Pharm Ther. 2010;15(8):894-900.

13. Gao RL. [The efficacy and safety of rosuvastatin on treating patients with hypercholesterolemia in Chinese: a randomized, double-blind, multi-center clinical trial]. Zhonghua Xin Xue Guan Bing Za Zhi. 2007;35(3):207-211. Chinese.

14. Sun Y, Yao W, He ZS, Wang LY, Zhao XL, Li HM. Randomized, doubleblind, multicenter clinical trial on efficacy and safety of rosuvastatin on treating patients with hypercholesterolemia. Chin J Clin Pharm. 2010;26(5):326-329.

15. Wu ZY, Chen JZ, Yang K, Li HW, Zhang HQ, Yang PL. Clinical study for dose-effect and safety of rosuvastatin in patients with primary hypercholesterolemia. Chin Circ J. 2010;25(3):181-184.

16. Davidson MH. Rosuvastatin in elderly patients. Drugs Aging. 2007;24(11):933-44.

17. Wang YH, Huang CL. Comparison of clinical efficacy of rosuvastatin versus simvastatin for hyperlipidemia in elderly patients. Chin J Drug Appl Monit. 2009;6(4):203-205.

18. Wu LX. Efficacy and safety of rosuvastatin in aged patients with coronary heart disease and hypercholesterolemia. Chin Mod Med. 2013;20(9):70-71.

19. Cui GQ, Chen YJ. Efficacy comparison of rosuvastatin and simvastatin in treatment of elderly patients with coronary heart disease associated with hypercholestolemia. Chin Mod Med. 2013;20(9):70-71.

20. Han H, Xue J, Zhang JY, Xu FH, Wang YH. Efficacy and safety of rosuvastatin and atorvastatin in aged patients with hypercholesterolemia. Chin J New Drugs Clin Remedies. 2008;27(2):120-123.

21. Liu YX, Li H, Zhang ST, Fan Y, Han JX, Zhou J. The effect and safety of rosuvastatin in very elderly patients with hyperlipidemia. Chin J Health Care Med. 2010;12(5):392-393.

22. Huang M, Zhang DF. Application of rosuvastatin in aged patients with hypercholesterolemia. Chin J Cardiovasc Rehabil Med. 2010;19(6):634-636.

23. Guo YM, Huang ST. The analysis of statins using in the elderly patients with coronary heart disease. Chin J Cardiovasc Rev. 2012;10(9):652-654.

24. Liu SW, Wang XY, Ma JL, Li B. Effects of rosuvastatin on carotid intima media thickness and endothelium-dependent flowing mediated dilation in patients with hypercholesterolemia. Chin Hosp Pharm J. 2010;30(15):1275-1278. 
25. Yang W, Liu JY, Qin L. Rosuvastatin and atorvastatin in treatment of coronary heart disease. Chin Gen Pract. 2013;16(6):621-623.

26. Qian XS. Efficacy and safety of different doses of rosuvastatin on carotid atherosclerosis patients complicated with hyperlipidemia: a comparative study. J Clin Med Pract. 2012;16(11):27-30.

27. Gao LJ, Qi XY, Wang XP, et al. The influences of rosuvastatin on hyperlipidemia and carotid artery plaques in patients with carotid atherosclerosis. Chin Gen Pract. 2011;14(36):4153-4156.

28. Cao XZ, Jiang L. Effect of rosurastain on carotid plaques in patients with acute coronary syndrome. J Intern Intensive Med. 2009;15(5): 240-241.

29. Peng XL, Lin ZP, Teng H, Zhang RK, Zhang ZW. Effect of rosuvastatin on microalbuminuria and arteriosclerosis plaque of artery in hypertensive patients. Chin J Hypertens. 2009;17(8):733-736.

30. Chen $\mathrm{CH}$, Wang GY, Su H. Rosuvastatin and atorvastatin on coronary heart disease in patients with acute myocardial infarction clinical randomized controlled trial. Chin J Clin Pharmacol. 2013;29(2): $126-128$.
31. Shi R, Jiang TM, Zhao JH, et al. Clinical study of patients with premature acute myocardial infarction undergoing intervention with different statins treatments. Chin Gen Pract. 2012;15(23):2619-2622.

32. Lin ZP, Shu PC, Liao ZJ, Wang XP, Liu Q. [Rosuvastatin improves myocardial function and arteriosclerosis plaque in patients with STsegment elevation after acute myocardial infarction and percutaneous coronary intervention]. Nan Fang Yi Ke Da Xue Xue Bao. 2011;31(10): 1789-1791. Chinese.

33. Xie JH, Liu P, Guan HM, et al. Effects of early administration of highdose rosuvastatin on coronary microvascular function and short-term outcome in patients treated with primary PCI for acute myocardial infarction. Chin J Cardiovasc Rev. 2010;8(4):261-265.

34. Davidson MH. Rosuvastatin safety: lessons from the FDA review and post-approval surveillance. Expert Opin Drug Saf. 2004;3(6): 547-557.

35. Brewer HB Jr. Benefit-risk assessment of rosuvastatin 10 to 40 miligrams. Am J Cardiol. 2003;92(4B):23K-29k.
Clinical Interventions in Aging

\section{Publish your work in this journal}

Clinical Interventions in Aging is an international, peer-reviewed journal focusing on evidence-based reports on the value or lack thereof of treatments intended to prevent or delay the onset of maladaptive correlates of aging in human beings. This journal is indexed on PubMed Central, MedLine, the American Chemical Society's 'Chemical Abstracts

\section{Dovepress}

Service' (CAS), Scopus and the Elsevier Bibliographic databases. The manuscript management system is completely online and includes a very quick and fair peer-review system, which is all easy to use. Visit $\mathrm{http} / / / \mathrm{www}$.dovepress.com/testimonials.php to read real quotes from published authors. 